\title{
Directory of Open Access Journals (DOAJ)
}

\author{
Composite Score:
}

$\star \star \star \star 3 / 4$
Date of Review: August 17, 2007

\section{Product Description}

The Directory of Open Access Journals (DOAJ) is a free service, a librarian-vetted list of over 2,800 fully Open Access, peer-reviewed scholarly journals. DOAJ is growing at a rate of more than one title a day.

The DOAJ home page provides an overview of the DOAJ service, an up-to-date count of journals listed in DOAJ, how many journals can be searched at the article level through DOAJ, and how many articles can be retrieved through such a search. DOAJ is currently used primarily by libraries and serials support services (such as Serials Solutions, SFX, reSearcher) as a means of identifying scholarly Open Access journals, and connecting people with Open Access information through link resolving services.

The DOAJ Find Journals page is the primary search screen for DOAJ, and it illustrates the beautiful, clean lines and layout that make DOAJ so easy to understand and to use (Figure 1). The DOAJ interface allows users to Find Journals, Browse by Title (alphabetic), or Browse by Subject (hierarchical, discipline-based), which is likely to be very useful for academic liaison libraries. Search results appear quickly.
To initiate a find journals search, users simply type in the box at the top of the screen and click on Find Journals; this starts a search of all the metadata associated with the journal. The Find Journals search is useful for a known title or topic searching. For example, as illustrated in Figure 2, a search for "nanotechnology" yields a list of five titles. Information provided for each title includes Titles, ISSN, Subject, Publisher, Language, Keywords, and Start Year. (The Start Year is the first year for which issues are available as Open Access; older journals that have not digitized back issues may have been publishing since before the Start Year). Find Journals can also be used for other types of searches. For example, a search for Public Library of Science or PLoS yields the seven titles currently available from this Open Access publisher.

DOAJ Subjects are organized by a disciplinary-based hierarchy. Clicking on Expand Subject Tree brings up the full list of subject headings and subheadings.

Downloading title lists is a bit more complex, well designed for inclusion of title lists in library catalogues and link resolving services. This feature can be found under About DOAJ / Metadata Information.

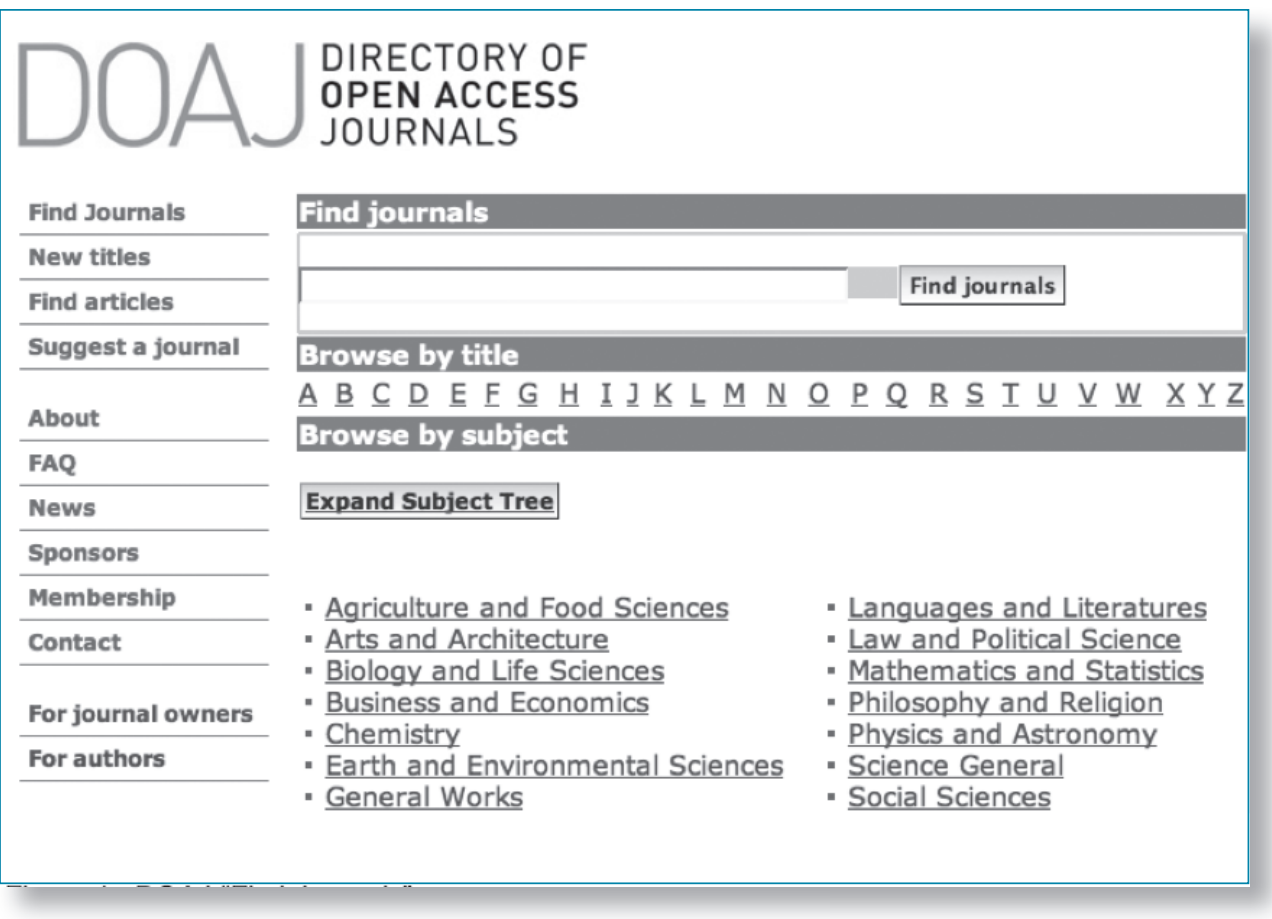

The DOAJ expandable subject tree is illustrated in Figure 3 by the hierararchy of Health Sciences, which is divided into four general subject headings. Clicking on the name of a subject heading - in this case Medicine (General)_brings up the list of Open Access journals in that area. Each list has a stable, persistent URL, very useful for links in a subject pathfinder, as a list that is automatically updated with changes in DOAJ. 
FIGURE 2 Nanotechnology Search Results.
A new feature is the DOAJ search for Open Access and hybrid journals for authors wishing to publish Open Access (Figure 4). All the DOAJ features are available, and in addition, authors can choose to limit to journals without (or with) a publication fee.

The DOAJ Find Articles search features Boolean logic and field-specific searching. Less than a third of DOAJ journals support article-level searching at present, which significantly limits the usefulness of this search feature.

\section{Critical Evaluation}

DOAJ is the most recognized and most authoritative list of scholarly, peer-reviewed, fully Open Access journals. More than 10 percent of the world's peer-reviewed journals are now included in DOAJ, making DOAJ among the world's largest collections of peer-reviewed scholarly journals, period. There are more peer-reviewed journals in DOAJ than Science Direct ${ }^{1}$; more nonembargoed, peer-reviewed journals in DOAJ than in EBSCO's Academic Search Premiere or Gale's OneFile. ${ }^{2}$ Full Open Access means no journals are embargoed, and articles are available for use, a significant strength of DOAJ.

The DOAJ vetting process involves querying journal editors to ensure that peer-review or equivalent quality controls are in place and that journals meet the criterion of true Open Access per the Budapest Open Access Initiative definition. ${ }^{\mathbf{3}}$ To be included in DOAJ, a journal must have an ISSN. Journals included in DOAJ go through a periodic review process to ensure that the journal continues to meet the criteria for inclusion.

The aesthetically pleasing and highly functionally DOAJ interface adds significantly to user confidence in DOAJ. The price (free) and contract terms (Open Access per the

FIGURE 3 DOAJ Health Sciences showing the four general subject headings. The expanded view of Medicine (General) shows the available Open Access journals for that subject heading.
Budapest Open Access Initiative definition) cannot be beat. Minor suggestions for improvement include addition of an Advanced Search option, true keyword searching, and a user-friendly title list download option to facilitate creation of bibliographies of journals.

One of the strengths of DOAJ is its diversity, reflecting a much broader range of linguistic content and origin of research than typical Western-based journal packages.

As a free service, including DOAJ in library services is recommended for all libraries, whether in journal A-Z lists, library catalogues, link resolvers, or Web sites. Subject-specific URLs can easily be generated for inclusion in subject guides and pathfinders.

Browse by subject

\section{Expand Subject Tree}

Subjects , Health Sciences

- Dentistry (29 journals)

- Medicine (General) (236 journals) " Public Health (89 journals)

\section{Browse by subject}

\section{Expand Subject Tree}

Subjects, Health Sciences, Medicine (General)

- Allergy and Immunology (14 journals)

- Cardiovascular (38 journals)

- Dermatology (9 journals)

- Gastroenterology (16 journals)

- Gynecology and Obstetrics (20

journals)

- Internal medicine (128 journals)

- Neurology (46 journals)

- Oncology (24 journals)

- Ophthalmology (9 journals)
- Otorhinolaryngology (7 journals)

- Pathology (12 journals)

- Pediatrics (30 journals)

- Pharmacy and materia medica (19 journals)

- Psychiatry (27 journals)

- Sports Medicine (6 journals)

- Surgery (50 journals)

- Therapeutics (34 journals)

- Urology (11 journals) 


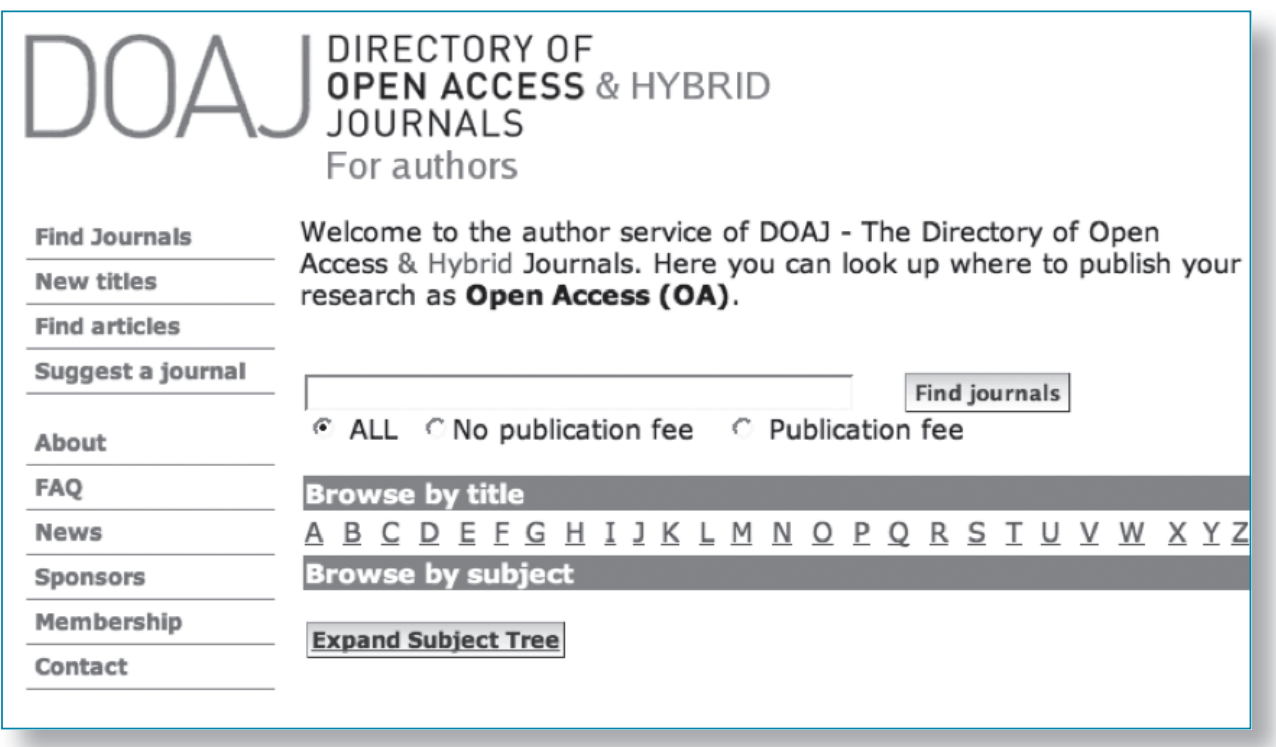

FIGURE 4 DOAJ Journal Search

DOAJ welcomes journals in any language; many journals feature content in more than one language. English is the most frequently cited language. Of the 2,331 DOAJ journals, 83 percent are in English, or mixed language content including English. There are 646 titles including some Spanish content,

\section{CONTENT}

The Directory of Open Access Journals (DOAJ) is a librarian-vetted list of fully Open Access, peer-reviewed scholarly journals. From the DOAJ Selection Criteria, for a journal to be included in DOAJ, it "must exercise peer-review or editorial quality control to be included." This is an exceptionally clear definition; there are many forms of academic quality control, and defining peer review is much more complex than it would, at first, appear. The DOAJ definition is much clearer than Ulrich's (considered an authoritative traditional list of subscription-based journals), which provides no definition at all for what it calls "refereed" journals.

There are about 20,000 to 25,000 peer-reviewed journals in the world. Crow cites 20,000 active, peer-reviewed journals. According to Uhlrich's, on July 27, 2007, there are 23,488 active, academic/scholarly, refereed journals in the world. ${ }^{5}$ As of September 8, 2007, the Directory of Open Access Journals includes 2,832 journals, more than 10 percent of the world's estimated 20,000 to 25,000 peer-reviewed scholarly journals. Of these, 844 are searchable at the article level, and a total of 142,784 articles are included.

It is noteworthy that the number of journal titles included in DOAJ is impressive compared with commercial journal packages. DOAJ's 2,832 journals compares favorably with the approximately 2,000 titles in Science Direct, for example. 1 EBSCO's Academic Search Premiere includes 1,503 nonembargoed, peer-reviewed, scholarly, fulltext journals, as of July 2007, just over half the number of comparable titles in DOAJ. Academic Search Elite includes 537 full-text, peerreviewed, scholarly titles with no embargo period and content indicated as "to present," 19 percent of the number of comparable titles in DOAJ. Gale's Academic OneFile includes 2,013 fulltext, refereed, nonembargoed journals, 71 percent of the title count of DOAJ.

This does not mean that DOAJ is equivalent in content to these commercial packages, as the number of articles may differ. Also, commercial packages are developed with very different selection criteria than DOAJ, and some include additional content such as indexing to other journals. The comparison of number of titles, however, is a useful means of illustrating that Open Access publishing has already reached a very significant point in terms of amount of content.
318 Portuguese, 221 French, 153 German, 82 Italian, 65 Japanese, 48 Turkish, 35 Croatian, 32 Russian, 13 Chinese, 11 Norwegian, 10 Swedish, and 6 Serbian; other languages are represented as well. The diversity of DOAJ is one of its strengths; searching or browsing titles in DOAJ provides a much broader perspective than traditional Western-based search resources.

Journals in DOAJ cover a full range of academic areas. The precise number of titles in any area can easily be determined by following the subject tree. For example, there are 28 journals in Dentistry (under Health Sciences) and 78 journals in Library and Information Science (under Social Sciences).

Not surprisingly, many journals in DOAJ feature relatively recent start dates (defined as first issue that is openly accessible; the actual start date of a journal may be earlier than the DOAJ start date). However, DOAJ does include a number of journals that are clearly not recent start-ups. For example, one title in Physics has a start date of 1918, and the earliest start dates in Medicine and Mathematics are from the $1950 \mathrm{~s}$.

All titles in DOAJ are current. Ceased titles are removed from the list, unless replaced by another journal. One obvious advantage to this approach is that it makes it possible to use DOAJ as a rough measure of current, active Open Access journals.

Sally Morris and colleagues, early in 2005, conducted an informal study of the 1,443 journals included in DOAJ at that time. ${ }^{6}$ Responses were received on 1,213 journals. This study uncovered some journals that were inaccessible, no longer Open Access, or not original journals, important information that likely inspired a DOAJ weeding project and improved ongoing verification procedures. Eliminating these journals, it was found that the remaining journals were, on average, longer-established than is generally supposed, with a median start date of 2000. The number of articles per journal varied widely, from 1 to 8,700 , with an average annual output of 42 articles. This study counted articles for 1,141 journals, and found a total of 316,790 Open Access articles, compared to the more than one million free articles available, mostly through delayed access, at Highwire Press.

The finding of 316,790 articles from 1,443 journals is interesting compared to the just over 142,000 articles available from article search in 
DOAJ today, based on the over 2,800 titles in DOAJ. This strongly suggests that many of the Open Access journals included in DOAJ could enhance discoverability of articles in their journals by working on making them searchable at the article level.

It is important to note that this study is already significantly outdated, as DOAJ has, since the time of counting, undergone a rigorous weeding process and improved ongoing verification procedures. And still, the number of titles has doubled, despite the tighter process for including titles.

One of the conclusions in Morris' study is significantly erroneous, based on incorrect understanding of the data. This is described in detail in the author's blogpost, DOAJ: Strong Growth, and Understanding the Numbers. ${ }^{7}$ That is, Morris concluded that Open Access journal start-ups peaked in 2001, and have been declining ever since. An analysis of DOAJ start dates in 2007 reveals an opposite conclusion. When Morris and her colleagues were counting, there were more journals in DOAJ with a start year of 2001 (just under 180) as compared with 2004 (80). In September 2007, 2004 in DOAJ is no longer a valley, but rather a small peak, with 311 journals with this start year (as compared to 295 with a start year of 2001). It is likely that the reason for this error is failing to take into account the lag time between start-up of a new Open Access journal and its inclusion in DOAJ. The reasons for the lag time are the need for discovery or presentation of the new title and the DOAJ vetting process. Currently, DOAJ checks for Open Access status, peer review or equivalent academic quality control, and also sufficient article publication to merit inclusion in DOAJ. This means that growth in Open Access publishing will always be underestimated by relying on recent DOAJ start year data.

The Kaufman-Wills study of Open Access journals of 2005 found that about 10 percent of the 1,300 journals listed in DOAJ at the time of study did not have current contact information. ${ }^{\mathbf{8}}$ This information was passed along to DOAJ to assist with improving the title list.

Since 2005, DOAJ has been actively checking and weeding DOAJ. Titles are deleted if they no longer meet the DOAJ criteria (e.g., if their Open Access status changes). Open Access titles, like other serials titles, frequently change titles and other details, so this verification process helps to ensure the ongoing quality of DOAJ.

From the author's perspective, there may be good reasons to retain titles no longer currently being published in DOAJ. If the journal is still accessible and the articles meet standards of quality and Open Access, the reader is well served by leaving the title in DOAJ. Perhaps retaining ceased titles, and adding a field in DOAJ to indicate cessation of a title and searching facilities to allow for inclusion or exclusion of ceased titles, would improve the utility of DOAJ.

Another conclusion of Morris' was that the DOAJ listing overestimates the number of active Open Access journals. There is significant counterevidence to this claim. DOAJ is not the world's largest list of Open Access titles. Librarian Jan Szczepanski of Göteborg University, one of the primary contributors of title suggestions to DOAJ, has collected information on over 4,500 current and 700 historic Open Access journals. Sczcepanski's lists are available for download from <http://www.his.se/templates/vanligwebbsida1.aspx?id=20709>.

Open J-Gate <http://www.openj-gate.com/> claims to be the "World's Biggest English Language Journals Portal”, with 4,148 Open Access Journals, including peer-reviewed and professional/industry journals. Assuming about half are peer-reviewed scholarly journals, this results in an estimated English-language, peer-reviewed journal title count of 2,074, slightly less than the over 2,300 titles with English content listed in DOAJ. ${ }^{9}$ Open J-Gate is a portal to article-level searching, and hence not directly comparable with DOAJ. The size and functionality of Open J-Gate are significant, and this resource merits its own review.

DOAJ features a searchable list of Open Access and hybrid publishers for authors wishing to publish in Open Access journals. Authors can elect to search by whether or not a journal charges publication fees.

One disadvantage of the vetting process is that it can mean a delay in appearance of new journals in DOAJ. It might be helpful to provide a list of suggested titles, and/or titles under consideration. Libraries may choose to add these to their own journals list, or exclude them knowing that they will be added to DOAJ in the near future, or this could be a helpful lookup for those considering suggesting new titles.

\section{SEARCHABILITY}

The DOAJ search screen is highly functional, well organized, and aesthetically pleasing. The DOAJ main page provides three search options: Find Journals (a keyword search that can also be used to search for journals by title), Browse by Title, and Browse by Subject.

The menu at the left-hand side of the screen provides additional options, such as viewing New Titles, Find Articles, Suggest a Journal, links to information about DOAJ, links to information for journal publishers (password protected) and authors.

Ruecker et al. explain that one of the key purposes of aesthetics in computer interface design is to inspire the user's confidence. ${ }^{\mathbf{1 0}}$ The elegant design of the DOAJ interface adds to the well-known DOAJ vetting process, to inspire considerable confidence in the list.

The Find Journals feature is very useful, but could be improved by including true keyword search functionality. For example, an exact title search is supported, but not a keyword title search; a search in DOAJ for "Partnership" yields the title Partnership: the Canadian Journal of Library and Information Practice and Research, while keyword searches for "Canadian library journal" or "partnership journal" yield no results.

The expandable Subject Tree is very useful. Each Subject list and sublist has its own URL, which can be added to library subject guides or pathfinders. This provides a list of fully Open Access, peer-reviewed journals in a particular subject area, which is automatically kept up to date. For example, the Library and Information Studies URL is $<$ http://www.doaj.org/doaj?func=subject\&cpid=129>, which currently brings up a list of 78 journals; if more titles are added, the URL remains the same.

The New Titles feature is helpful, but could be improved with the addition of RSS and e-mail feeds. Article-level searching is available for 844 of the 2,803 journals in DOAJ. DOAJ supports Boolean logic and field-specific searching. Title lists can be downloaded in Excel format.

Earlier this year, DOAJ announced a new OAI-PMH metadata format called "doajarticle"; details can be found at <http://www.doaj.org/ doaj?func=loadTempl\&templ=070509>. The new schema includes elements for ISSN/eISSN, volume/issue, start/end page numbers, and author affiliation. There is also a $<$ fullTextUrl $>$ element that is a link to the article content itself. Publishers are well advised to provide the fullest possible metadata for each article; this facilitates article-level 
searching within DOAJ, as well as link resolving and inclusion of articles in local article repositories such as OhioLINK's Electronic Journals Centre. ${ }^{\mathbf{1 1}}$ Note: while the start page is an important key for link resolving (to identify an individual article), this may not be relevant for electronic-only journals. An alternative, predictable article identifier, whether numbering articles within a given issue or volume, or using author or title information, may be preferable.

DOAJ journal lists are available through a number of link resolving and serials management products, including SFX, Serials Solutions MARC records service, the reSearcher open source suite, and Ex Libris.

Advanced search capability would be a welcome addition. For example, it would be helpful to be able to search by language, country of origin, or by combining subject headings with other search options. This will become increasingly important as the list grows.

A more robust keyword Find Journals search would be useful as well. At present, for example, a journal title can be found with an exact title search but not with select title terms. A search for "Partnership" yields Partnership: the Canadian Journal of Library and Information Practice and Research; however, a search for "Partnership Journal" yields no matches.

\section{Pricing}

DOAJ is a completely free service, so in this sense the price cannot be beat! For an Open Access initiative, the key question is whether DOAJ has an economically sustainable infrastructure. On February 13, 2007, DOAJ launched a Membership program.

Membership Categories and Annual Fees are:

Individuals

Libraries, Universities, Research Centers

Library Consortia, Library Associations

Aggregators and other Service Providers

There is an optional "Supporter" category for those who would like to support DOAJ, but cannot afford the Membership fees. Two methods of payment are provided, Bank Transfer or Invoicing.

First, let us consider the annual membership fee for an individual library (Libraries, Universities, Research Centers), 400 Euros or approximately $\$ 550$ U.S. Without DOAJ, there would be two options for individual libraries: a) the library could undertake the work of collecting and vetting these titles, or b) do without the content. Either way, the annual membership fee for DOAJ is a sound investment.

Many libraries are involved in collecting Open Access titles that fall outside the scope of DOAJ, so will be very aware of the work involved. The tasks of identifying, vetting, and making accessible more than 2,800 titles, with more than one new title added per calendar day, is more than a full-time job for a professional librarian. The annual membership fee of 400 Euros is a pittance in comparison with the cost to an individual library to undertake this work on its own.

The staffing benefits of DOAJ membership are illustrated by the ability of DOAJ to hire an additional librarian based on early membership commitments, a key factor in DOAJ being able to speed up processing and including new titles and ensuring quality control through verification of existing titles and weeding.

Looking at the value of DOAJ from a content perspective, it is an incredible bargain. DOAJ provides access to more than 2,800 peer-re- viewed, scholarly journals at an annual membership fee that is lower than the average price for one title for any scientific discipline (the lowest average price being Agriculture, at $\$ 898$ U.S.) (Van Ordsel and Born). ${ }^{12}$

While the services of DOAJ are, and will remain, free, there are benefits to membership, primarily acknowledgement on the DOAJ Membership pages, and the right to use DOAJ membership in marketing activities. There are some functional benefits to membership as well, including access to the list of recently added titles and the list of removed titles.

For the individual library of any type, the right to use DOAJ membership in marketing activities is a significant benefit to position the library for leadership in the internet age. DOAJ membership demonstrates library support for Open Access to quality scholarly materials on the Web. DOAJ membership illustrates that the library works actively to connect information seekers with quality, free resources when it is possible to do so. For academic libraries, the ability to use DOAJ membership in marketing activities is important in the key emerging area of scholarly communications.

The annual membership fee of 4,000 Euros (approximately \$5,500 U.S.) for library consortia is also a great bargain (with the exception of consortia with less than 10 members) for the same reasons that DOAJ is a bargain for the individual library (staff time savings, content).

For consortia with fewer than 10 members, or consortia who might wish to pursue an opt-in approach to DOAJ membership, alternative approaches such as discounts on membership for individual libraries based on group participation would help. For example, DOAJ might wish to consider a 5 percent discount for groups of five or more libraries purchasing membership together if libraries are paying separately, or a 10 percent discount for groups of five or more libraries when a single payment is involved.

Libraries, and library consortia, vary a great deal in size and type. Generally, a one-price-fits all approach is not recommended; however, in the case of DOAJ, annual membership fees for either individual libraries or consortia are so reasonable, that, in the author's opinion, it is not advisable to provide lower prices for smaller libraries.

The library association category, at the same price as the library consortium category, will sometimes makes sense, as library associations sometimes fill the same functions as library consortia, that is, coordinating group purchases. However, this is not a core function for the majority of library associations, and DOAJ might wish to consider a lower membership fee for library associations (and other associations) wishing to provide support for DOAJ. Perhaps something along the lines of a fee of 100 Euros per 1,000 association members would be workable.

One membership category that seems to be missing is Open Access and hybrid publishers. While the DOAJ service should remain free for publishers, it is a highly significant benefit for this group, and some might wish to join. Since publishers are already contributing significantly through content and information, and to avoid potential conflicts of interest, perhaps a low membership fee of about 40 Euro per journal, capped at half of the publisher's highest article processing fee, or 400 Euros for a large publisher with no article processing fees, would be workable. To ensure best service for DOAJ, membership benefits for publisher members should be restricted to acknowledgement and promotion of DOAJ membership. 
The membership fee of 100 Euros for individual members seems high. If DOAJ wishes to receive significant revenue from individual memberships, then DOAJ should investigate tax credits for contributions and provide a variety of contribution options and amounts, including one-time contributions as well as annual fees. Perhaps DOAJ might consider developing a "Friends of DOAJ" group to undertake this kind of fundraising effort.

A number of aggregators and service providers have signed up either as members or sponsors, which suggests that DOAJ pricing for these groups is appropriate. The annual membership fee is 5,000 Euros; the amount for sponsors is not listed. DOAJ is very popular with libraries. It is a highly recognizable service with a reputation for quality and it is aesthetically pleasing. Membership or sponsorship in DOAJ is a wise investment for any vendor providing services to libraries.

The flexibility of DOAJ in providing an option for supporters who cannot afford the DOAJ membership fee, provided on the basis of requests from libraries and others in the developing world that cannot afford the membership fees, is a step in the right direction. Another, perhaps fairer, approach would be to provide a membership option with flexible pricing to allow libraries and others in the developing world to participate as full members in an equitable manner.

One means to calculate equitable participation would be to translate membership fees into a salary equivalent (the potential member could take the responsibility of calculating the appropriate amount). For example, the membership fee of 400 Euros for an individual library translates to about $\$ 575$ Canadian, equivalent to about 28 hours (four days) of wages at the average hourly wage of $\$ 20.20$ for Canadians. ${ }^{13}$ An equitable approach would be to allow a library in the developing world to participate as a full member with a contribution equal to four days work at the local average hourly wage. To avoid complexity, DOAJ could offer this option only where the difference is significant. This approach would allow DOAJ to maximize the promotional benefits of the membership program. If DOAJ were to employ such an approach, it could be a role model not only for Open Access, but also as a global participation model. Other types of membership could similarly be translated into local equivalents to allow for full participation by developing countries.

Another potential membership category is national libraries. DOAJ is having discussions with the Royal Library of the Netherlands about the possibility of archiving of the Open Access journals within DOAJ. For security, preservation and ongoing access, the more copies of the content, the better. Every national library should consider joining DOAJ, with a view to eventually harvesting and archiving a copy of all of the journals in the long term, and at the very least collecting journals associated with their own country in the short term. The nature and functions of national libraries vary considerably. Some might act as national consortia and purchase DOAJ membership on behalf of all libraries in a country; in other cases an amount recognizing support for DOAJ might be more appropriate. In this case, a membership fee based on the country's population might be a good starting point (e.g., \$100 Euros/one million population).

\section{Contract Options}

The definition of "Open Access" provided by the DOAJ is:

We define Open Access journals as journals that use a funding model that does not charge readers or their institutions for access. From the BOAI [Budapest Open Access Initiative] definition of "Open Access" we take the right of users to "read, download, copy, distribute, print, search, or link to the full texts of these articles" as mandatory for a journal to be included in the directory. (From the DOAJ About page, at: <http://www. doaj.org/doaj?func=loadTempl\&templ=about>.)

This is the ideal terms and conditions. Articles are not only free, but also available for use: for the data mining that will facilitate new forms of research, for reading, for redistribution.

Most of the journals in DOAJ provide articles in formats that fit these ideal conditions. Some journals publish articles in locked-down PDF format, however. Ensuring that Open Access articles are usable, not just readable, is important for a number of reasons, such as enabling data mining and new forms of research based on data mining, as well as for making materials available to the print disabled. This is likely a learning curve for everyone involved in Open Access publishing, Open Access and subscription-based alike.

\section{Conclusion}

The Directory of Open Access Journals is a significant resource. DOAJ has developed a well-deserved reputation for quality, and is the world's most authoritative list of fully Open Access, peer-reviewed titles. The size of the title list in DOAJ is very impressive, and compares favorably with commercial options. DOAJ is growing dramatically. The service provided by DOAJ is so obviously important, and the membership fees such an incredible bargain, that it seems highly likely that ongoing economic security will be a reality for DOAJ in the not too distant future. Libraries, consortia, universities, and research centres should consider membership; vendors serving the library community are well advised to consider DOAJ membership or sponsorship.

\section{Contract Provisions}

Full Open Access, with no embargo, and with the ability for the user to "read, download, copy, distribute, print, search, or link to the full texts of these articles" per the Budapest Open Access Initiative, is mandatory for inclusion in DOAJ. This is a significant strength of DOAJ. No permission is needed to hand out articles in class, include in e-reserves, or share with anyone, inside or outside your own institution. The search provision is very important, as this will facilitate data mining and research based on artificial intelligence.

\section{Authentication}

As an Open Access initiative, no authentication is needed, another significant benefit of DOAJ. No authentication means less work, and less troubleshooting.

\section{Comments from Selected Users}

DOAJ is used by libraries and others throughout the world, directly as a search tool, posted on library Web sites, through inclusion in A-Z journal title lists and library catalogues, and as a lookup for link resolvers. Thanks to the following people who replied to a question posted to ERiL-L, the SPARC Open Access Forum, and OA Librarian, as well as others who responded privately.

The University of Minnesota Duluth Library (not a member) is fairly typical. DOAJ has been activated in their link resolver and A-Z list (SFX), and DOAJ titles are added to their library catalogue on 


\section{Directory of Open Access Journals (DOAJ) Review Scores Composite: $\star \star \star \star 3 / 4$}

The maximum number of stars in each category is 5 .

\section{Content:}

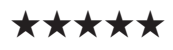

DOAJ is the world's most authoritative list of current, fully Open Access, peer-reviewed journals. It includes over 2,800 journals, and more than one new title is added every day.

\section{Searchability: $\quad \star \star \star \star \quad 1 / 2$}

Clean, aesthetic, highly functional interface with a variety of search options. Could use a more robust keyword search option and advanced search functionality.

\section{Contract Options: $\quad$ N/A.}

Open Access per the Budapest Open Access Initiative means that journals included in DOAJ are not only free, but available for use-no permission needed to hand out in class, for e-reserves or coursepacks, data mining to support new approaches to research.

\section{Pricing: N/A}

Free. Membership and sponsorship options available.

a monthly basis using Marc-It. As reported by Sunshine Carter on ERiL-L, "DOAJ gets a fair amount of use through our link resolver. In the last two years, our DOAJ target is ranked \#27 in terms of clickthroughs (out of 222 active targets)."

Donnice Cochenour and Nancy Chaffin Hunter of Colorado State University Libraries report a similar pattern of usage of DOAJ. Colorado State University Libraries has not yet considered DOAJ membership but may do so in the future. Brenda Braham, Montgomery College Library, reports that DOAJ is set up with their Serials Solutions Article Linker and federated search, and that they also receive MARC records for DOAJ titles. Otherwise her library does not include free resources with proprietary databases.

Houdeida K. Charara of the Lebanese American University Libraries reports that DOAJ is listed on their Open Access Resources and Online Databases Web pages, and indicated that DOAJ membership may be considered in future.

One respondent reported privately that DOAJ titles are included in their catalogue and Serials Solutions A-Z list, but that their limited budget does not permit DOAJ membership. Even with a small budget increase, they anticipate cutting some serials subscriptions in the near future.

DOAJ currently has 55 members or sponsors: 7 sponsors, 41 library/ university research centre members, 5 library consortia members, 1 Aggregator Service Provider member, and 1 individual member.

Don Taylor of Simon Fraser University Library (a DOAJ member) comments: "The membership dues seem decent, and you do get extra benefits for it, so that's good." It appears that a number of libraries are likely to join the DOAJ membership program in the near future. For example, the University of Calgary's Andrew Waller comments: "My library is not a member though we should probably join. We've joined and supported many other ventures and DOAJ is of increas- ing importance so it makes sense. Plus, the cost is pretty low (400 Euros = about $\$ 573 \mathrm{CAN})$." In response to the question, is there anything DOAJ should or could do to make its membership program more attractive, Andrew comments: "Probably not. It's a good deal as is. I think more advertising, especially on a regular basis, would be wise... When I looked at the list of current members ... I thought. 'there are a lot of libraries that could and should join.",

\section{Author's Annotated References}

Kaufman-Wills. The Facts About Open Access. Association of Learned and Professional Society Publishers (ALPSP) Research Report. 24 October 2005. Available for free download from <http:// www.alpsp.org/ngen_public/default.asp?ID=200>.

Note: This is a not a review, but a study of Open Access journals, using DOAJ to develop a contact list. It is significantly outdated; there were only 1,300 journals in DOAJ at the time (compared to over 2,800 at present). Also note the Addendum, correcting an error in the study that resulted in a significant underestimate of peer-review by Open Access journals.

Morris, Sally. Personal View: When is a Journal Not a Journal? Learned Publishing 19:1 (January 2006).

Note: This is a nonpeer-reviewed opinion piece based on a study of DOAJ conducted by 21 volunteers. It presents some interesting data and perspectives; however it is important to note that it is significantly out of date, as the number of journals in DOAJ has doubled since the time of the study, and it comes to conclusions not justified by the data presented as the lag time between development of an Open Access journal and inclusion in DOAJ is not factored in.

Morrison, Heather. DOAJ: Strong Growth: Understanding the Numbers. The Imaginary Journal of Poetic Economics, September 5, 


\section{Contact Information}

\section{The Directory of Open Access Journals}

The Directory of Open Access Journals is hosted and maintained by Lund University Libraries-Head Office

Lunds universitet Box 117, 22100

Lund, Sweden

\section{Project Coordinators}

Lotte Jørgensen, Librarian

Anna-Lena Johansson, Librarian

E-mail: <Anna-Lena.Johansson@lub.lu.se>

Sonja Brage. Librarian

E-mail: <Sonja.Brage@lub.lu.se>

URL: $\quad$ <http://www.doaj.org/>

2007 <http://poeticeconomics.blogspot.com/2007/09/doaj-stronggrowth-and-understanding.html $>$.

\section{Notes}

1. Science Direct Web site. Over 2,000 journals in Science Direct. Viewed August 14, 2007. <http://www.sciencedirect.com/

2. EBSCO and Gale nonembargoed full-text journals estimates are based on title lists provided by the vendors. Embargoed titles are subtracted from the total number of peer-reviewed full-text journals. For example, of the 3,718 peer-reviewed full-text journals listed in Academic Search Premier, 2,017 had a 12-month embargo. For the Academic Search Elite estimate, journals with no embargo but with a fulltext end date of not "to present" (i.e., not embargoed but not current) were also deducted. Title lists were downloaded from the vendors' Web sites. Detailed calculations available on request.

3. Budapest Open Access Initiative http://www.soros.org/openaccess/

4. Crow, Raym. Publishing Cooperatives: An Alternative for Society Publishers. A SPARC Discussion Paper. p. 4. Scholarly Publishing and Academic Resource Coalition (SPARC) 2006. Download from: http://www.arl.org/sparc/publications/papers.html
5. Ulrich's Periodicals Directory. Viewed August 2, 2007. http:// www.ulrichsweb.com/ulrichsweb/

6. Morris, Sally. Personal View: When is a Journal Not a Journal? Learned Publishing 19:1 (January 2006).

7. Morrison, Heather. DOAJ: Strong Growth: Understanding the Numbers. The Imaginary Journal of Poetic Economics September 5, 2007 http://poeticeconomics.blogspot.com/2007/09/doajstrong-growth-and-understanding.html

8. Kaufman-Wills. The Facts About Open Access. Association of Learned and Professional Society Publishers (ALPSP) Research Report. 24 October 2005. Available for free download from: http://www.alpsp.org/ngen_public/default.asp?ID=200. $\quad 1,300$ journals in DOAJ at the time.

9. According to the Open J-Gate Web site, over half the journals in Open J-Gate are peer-reviewed. This information may be out of date, as 3,000 journals were mentioned as the total title count, while the current total is over 4,000. This information was viewed on the Open J-Gate Web site on August 13, 2007.

10. Ruecker, Stan, Stéfan Sinclair, and Milena Radzikowska. Confidence, Visual Research, and the Aesthetic Function. Partnership: the Canadian Journal of Library and Information Practice and Research, Vol 2, No 1 (2007). http://journal.lib.uoguelph.ca/index.php/perj/article/view/252

11. Murray, Peter, OhioLINK. Phone conversation August 14, 2007.

12. Van Orsdel, Lee C. \& Kathleen Born. Serial Wars: As open access gains ground, STM publishers change tactics, and librarians ask hard questions. Library Journal, 4/15/2007. http://www. libraryjournal.com/article/CA6431958.html?q=serial+prices

13. Statistics Canada. Average hourly wages of employees by selected characteristics and profession, unadjusted data, by province (monthly). http://www40.statcan.ca/101/cst01/labr69a.htm. Viewed August 14, 2007.

\section{About the Author}

Heather Morrison is a Project Coordinator with BC Electronic Library Network (ELN), a member consortium of the International Coalition of Library Consortia. She is actively involved in the Open Access movement and has experience with developing models for purchase of electronic resources for library consortia. Heather received her M. L. I. S. from the University of Alberta is 1998, and has published in Research Strategies, Library Hi Tech, and Library Hi Tech News, among others. 